ARTICLE

\title{
Nanohybrids of a MXene and transition metal dichalcogenide for selective detection of volatile organic compounds
}

Winston Yenyu Chen ${ }^{1,2}$, Xiaofan Jiang ${ }^{2,3}$, Sz-Nian Lai ${ }^{4}$, Dimitrios Peroulis ${ }^{2,3}$ \& Lia Stanciu (1) 1,2凶

Two-dimensional transition metal carbides/nitrides, known as MXenes, have been recently receiving attention for gas sensing. However, studies on hybridization of MXenes and 2D transition metal dichalcogenides as gas-sensing materials are relatively rare at this time. Herein, $\mathrm{Ti}_{3} \mathrm{C}_{2} \mathrm{~T}_{\mathrm{x}}$ and $\mathrm{WSe}_{2}$ are selected as model materials for hybridization and implemented toward detection of various volatile organic compounds. The $\mathrm{Ti}_{3} \mathrm{C}_{2} \mathrm{~T}_{x} / \mathrm{WSe}_{2}$ hybrid sensor exhibits low noise level, ultrafast response/recovery times, and good flexibility for various volatile organic compounds. The sensitivity of the hybrid sensor to ethanol is improved by over 12 -fold in comparison with pristine $\mathrm{Ti}_{3} \mathrm{C}_{2} \mathrm{~T}_{\mathrm{x}}$. Moreover, the hybridization process provides an effective strategy against $M X e n e$ oxidation by restricting the interaction of water molecules from the edges of $\mathrm{Ti}_{3} \mathrm{C}_{2} \mathrm{~T}_{\mathrm{x}}$. An enhancement mechanism for $\mathrm{Ti}_{3} \mathrm{C}_{2} \mathrm{~T}_{x} / \mathrm{WSe}_{2}$ heterostructured materials is proposed for highly sensitive and selective detection of oxygencontaining volatile organic compounds. The scientific findings of this work could guide future exploration of next-generation field-deployable sensors.

\footnotetext{
${ }^{1}$ School of Materials Engineering, Purdue University, West Lafayette, IN 47907, USA. ${ }^{2}$ Birck Nanotechnology Center, Purdue University, West Lafayette, IN 47907, USA. ${ }^{3}$ School of Electrical and Computer Engineering, Purdue University, West Lafayette, IN 47907, USA. ${ }^{4}$ Department of Materials Science and Engineering, National Tsing Hua University, Hsinchu 30013, Taiwan. ${ }_{\text {email: Istanciu@purdue.edu }}$
} 
$\mathrm{T}$ he significance of wearable and wireless technologies has been increasing rapidly with internet of things (IoTs) ${ }^{1,2}$, in which sensors are crucial components deemed necessary to collect massive amounts of information from surrounding environments. For example, volatile organic compounds (VOCs) are common air pollutants contributing to the formation of ground-level ozone and carcinogens, and are thus harmful to human health ${ }^{3}$. Therefore, it is important to develop a wirelessoperating gas sensor for IoTs with rapid, selective, sensitive, and reversible detection of VOCs at room temperature.

Two-dimensional (2D) MXenes are generally produced by etching the intermediate A layers of a $\mathrm{M}_{n+1} \mathrm{AX}_{n}$ phase, where $\mathrm{M}$, $\mathrm{A}$, and $\mathrm{X}$ represent an early transition metal, A-group element, and carbon (or nitrogen) element $(n=1,2$, or 3$)$, respectively ${ }^{4}$. Because of a combination of properties such as stable and easily tunable microstructure, high electrical conductivity, large chemically active surface, and adjustable hydrophilicity, lowdimensional MXenes and MXene-based nanocomposites have recently received considerable attention particularly to catalysis ${ }^{5-7}$, energy conversion/storage ${ }^{8-10}$, and biomedical applications $^{11-13}$. Their application to gas sensor design, however, is rarely studied, and only focuses on pristine MXenes $\left(\mathrm{Ti}_{3} \mathrm{C}_{2} \mathrm{~T}_{\mathrm{x}}\right.$, $\mathrm{V}_{2} \mathrm{CT}_{\mathrm{x}}$, and $\left.\mathrm{Ti}_{2} \mathrm{CO}_{2}\right)^{14-16}$. On the other hand, 2D transitionmetal dichalcogenides (TMDs) have been considered as promising sensing materials owing to their high surface-to-volume ratios, good adsorption properties, large number of active sites for redox reactions, and high surface reactivity ${ }^{17,18}$. Indeed, a significant number of literature reports have recently emerged regarding their integration into chemical sensors to detect various harmful gases, such as $\mathrm{NH}_{3}, \mathrm{NO}_{2}$, and $\mathrm{VOCs}{ }^{19}$. Nevertheless, previous studies reported that gas-sensing devices using simply a 2D TMD material typically have a high electrical resistance and lack of selectivity and/or recovery to target analytes, especially at room temperature ${ }^{19}$, impeding their practical sensing applications to IoTs. To further improve their room-temperature sensing performance, 2D-TMDs have been fabricated vastly as alloybased heterostructures (e.g., $\left.\mathrm{Mo}(\mathrm{Se}, \mathrm{S})_{2}, \mathrm{WS}_{2 \mathrm{X}} \mathrm{Se}_{2-2 \mathrm{x}}\right)^{20}$, or incorporated with noble metallic nanoparticles (e.g., $\mathrm{Ag}, \mathrm{Nb}, \mathrm{Pt})^{21}$, metal oxides (e.g., $\left.\mathrm{SnO}_{2}, \mathrm{ZnO}, \mathrm{TiO}_{2}, \mathrm{Bi}_{2} \mathrm{O}_{3}\right)^{22}$, conducting polymers $^{23}$, or graphene (or its derivatives) ${ }^{24}$.

In summary, both MXenes and TMDs proved to have devicebeneficial physical and chemical properties (e.g., tunable band structures and microstructures), and each class of compounds has been individually studied extensively in recent years ${ }^{25,26}$. Incorporating TMD with MXene thus could be an effective strategy to further improve the room-temperature sensing performance of devices for VOCs. Besides hybrid MXene/TMD composites not being investigated for gas-sensing applications to date, most sensors reported in literature are fabricated by manual procedures, such as drop-casting, that can only be useful for laboratory scale production and suffer from lack of repeatability and precision. The lack of a pathway toward large-scale production is one of the main roadblocks toward bringing more sensors from the laboratory to the market, and one of the challenges we are addressing herein. The main approaches to synthesizing $2 \mathrm{D}$ functional materials are micromechanical exfoliation, liquid-phase exfoliation, ion intercalation-exfoliation, chemical vapor deposition, and wet chemical synthesis from molecular precursors ${ }^{27-29}$. Among these approaches, liquid-phase exfoliation appears to be the leading reliable, mass-production method for the wide-spread applications to gassensing devices. Such method avoids the use of dangerous airsensitive reagents and undesired property changes. Likewise, inkjet deposition of exfoliated materials is also a facile and repeatable process to fabricate devices at large scale.

Herein, we report on the synthesis of MXene $\left(\mathrm{Ti}_{3} \mathrm{C}_{2} \mathrm{~T}_{\mathrm{x}}\right)$ nanosheets and TMD ( $\mathrm{WSe}_{2}$ ) nanoflakes both through liquid- phase exfoliation, inkjet printing of $\mathrm{Ti}_{3} \mathrm{C}_{2} \mathrm{~T}_{\mathrm{x}} / \mathrm{WSe}_{2}$ hybrid sensors for selective detection of oxygen-containing VOCs and a sensing mechanism for the enhanced oxygen-based VOCs detection with $\mathrm{Ti}_{3} \mathrm{C}_{2} \mathrm{~T}_{\mathrm{x}} / \mathrm{WSe}_{2}$ nanohybrids. Moreover, inkjet printing offers repeatability of electrode fabrication and reproducibility of the sensing measurements, and is one avenue toward large-scale manufacturing of electrochemical sensors. We report on a sensing material design for gas-sensing application based on integrating the merits of two components: $\mathrm{Ti}_{3} \mathrm{C}_{2} \mathrm{~T}_{\mathrm{x}}$ nanosheets, with effective charge transfer, and $\mathrm{WSe}_{2}$ nanoflakes, with abundant active sites for gas adsorption. The $\mathrm{Ti}_{3} \mathrm{C}_{2} \mathrm{~T}_{\mathrm{x}} / \mathrm{WSe}_{2}$ nanohybrids show a unique morphology with numerous heterojunction interfaces, consequently facilitating a selective detection of oxygencontaining VOCs. The $\mathrm{Ti}_{3} \mathrm{C}_{2} \mathrm{~T}_{\mathrm{x}} / \mathrm{WSe}_{2}$ hybrid sensors exhibit an over 12 -fold increases in ethanol sensitivity compared to pristine $\mathrm{Ti}_{3} \mathrm{C}_{2} \mathrm{~T}_{\mathrm{x}}$ sensors. In addition, ultrafast response $(9.7 \mathrm{~s})$ and recovery $(6.6 \mathrm{~s})$ properties are achieved. We propose a sensing mechanism that is likely involved in the detection of oxygencontaining VOCs with $\mathrm{Ti}_{3} \mathrm{C}_{2} \mathrm{~T}_{\mathrm{x}} / \mathrm{WSe}_{2}$ heterojunctions and explains the observed enhanced sensing performance. A massproduction integration process (liquid-phase exfoliation and inkjet printing) and wireless operation of $\mathrm{Ti}_{3} \mathrm{C}_{2} \mathrm{~T}_{\mathrm{x}} / \mathrm{WSe}_{2}$ sensors at room temperature is demonstrated, thus opening an effective avenue for the development of high-performance sensing devices for next-generation IoTs.

\section{Results}

Sensor design. Figure 1a illustrates the process flow of preparing (1) $\mathrm{Ti}_{3} \mathrm{C}_{2} \mathrm{~T}_{\mathrm{x}}$ nanosheets from sequential etching and exfoliating of $\mathrm{Ti}_{3} \mathrm{AlC}_{2}$ powders and (2) $\mathrm{CTA}^{+}-\mathrm{WSe}_{2}$ nanoflakes from CTAB functionalized $\mathrm{WSe}_{2}$ powders, followed by a solution mixing method to form $\mathrm{Ti}_{3} \mathrm{C}_{2} \mathrm{~T}_{\mathrm{x}} / \mathrm{WSe}_{2}$ nanohybrids. The $\mathrm{Ti}_{3} \mathrm{C}_{2} \mathrm{~T}_{\mathrm{x}} / \mathrm{WSe}_{2}$ nanohybrids were further prepared as ink for the inkjet printing and the fabrication of flexible VOC sensors operating at room temperature using a wireless monitoring system (Fig. 1b). As evidenced from Supplementary Fig. 1, the thickness of the inkjet-printed $\mathrm{Ti}_{3} \mathrm{C}_{2} \mathrm{~T}_{\mathrm{x}} / \mathrm{WSe}_{2}$ layers was controllable by the number of printing passes, with a thickness of $\sim 60 \mathrm{~nm}$ per print pass

The functional block diagram and photographic image of the flexible wireless sensor system (Supplementary Fig. 2), along with a homemade sensor testing system (Supplementary Fig. 3 and Supplementary Table 1), are detailed in Methods. The feasibility of these processes to form the $\mathrm{Ti}_{3} \mathrm{C}_{2} \mathrm{~T}_{\mathrm{x}} / \mathrm{WSe}_{2}$ nanohybrids via electrostatic attraction can be evidenced from 80\%-potential measurements shown in Fig. 1c. The as-prepared $\mathrm{Ti}_{3} \mathrm{C}_{2} \mathrm{~T}_{\mathrm{x}}$ nanosheets are characterized by a negative charged surface with zeta potential of $-29.5 \mathrm{mV}$, which could be attributed to the negatively charged $-\mathrm{OH}$ and $-\mathrm{O}$ species terminated on $\mathrm{Ti}_{3} \mathrm{C}_{2} \mathrm{~T}_{\mathrm{x}}$ surfaces (verified later by XPS). On the other hand, the zeta potential of the pristine $\mathrm{WSe}_{2}$ was only $-1.5 \mathrm{mV}$. After exfoliation in $\mathrm{CTAB}$ aqueous solution, its surface charge was reversed, giving a substantial increase of zeta potential to $+30 \mathrm{mV}$. This polarity reversion suggests that $\mathrm{CTA}^{+}$cations indeed are effectively adsorbed on $\mathrm{WSe}_{2}$ nanoflakes, thereby facilitating the hybridization of $\mathrm{Ti}_{3} \mathrm{C}_{2} \mathrm{~T}_{\mathrm{x}}$ with $\mathrm{WSe}_{2}$ through electrostatic interaction.

The formation of as-etched $\mathrm{Ti}_{3} \mathrm{C}_{2} \mathrm{~T}_{\mathrm{x}}$ was further verified by XRD shown in Supplementary Fig. 4a. The removal of $\mathrm{Al}$ from $\mathrm{Ti}_{3} \mathrm{AlC}_{2}$ is revealed by the vanishing of (104) peak at $38.9^{\circ}$, along with the emergence of several peaks characteristics of $\mathrm{Ti}_{3} \mathrm{C}_{2} \mathrm{~T}_{\mathrm{x}}{ }^{30}$. Correspondingly, comparing the SEM micrographs in Supplementary Fig. 4b, c clearly reveals the transition from a bulk to an accordion-like structure upon the transformation of $\mathrm{Ti}_{3} \mathrm{AlC}_{2}$ to $\mathrm{Ti}_{3} \mathrm{C}_{2} \mathrm{~T}_{\mathrm{x}}$ nanosheets. The theoretical thickness of a $\mathrm{Ti}_{3} \mathrm{C}_{2} \mathrm{~T}_{\mathrm{x}}$ single layer is close to $1 \mathrm{~nm}^{31}$, and the MXene nanosheets tend to 


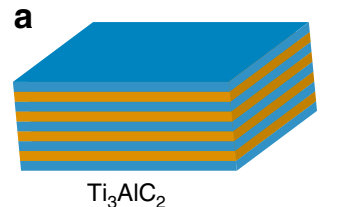

$\mathrm{Ti}_{3} \mathrm{AlC}_{2}$

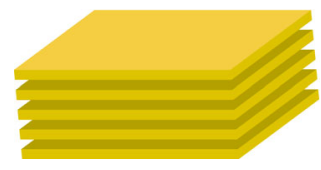

$\mathrm{WSe}_{2}$
HF etching

Exfoliation

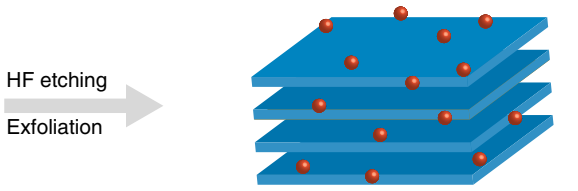

$\mathrm{Ti}_{3} \mathrm{C}_{2} \mathrm{~T}_{\mathrm{x}}\left(\mathrm{T}_{\mathrm{x}}=-\mathrm{O},-\mathrm{F},-\mathrm{OH}\right)$
Electrostatic
interaction

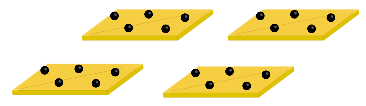

$\mathrm{CTA}^{+}-\mathrm{WSe}_{2}$

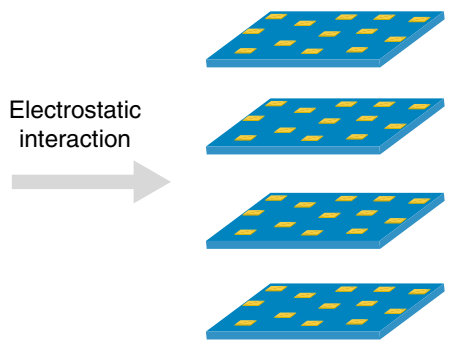

$\mathrm{Ti}_{3} \mathrm{C}_{2} \mathrm{~T}_{\mathrm{x}} / \mathrm{WSe}_{2}$ hybrids

b

C

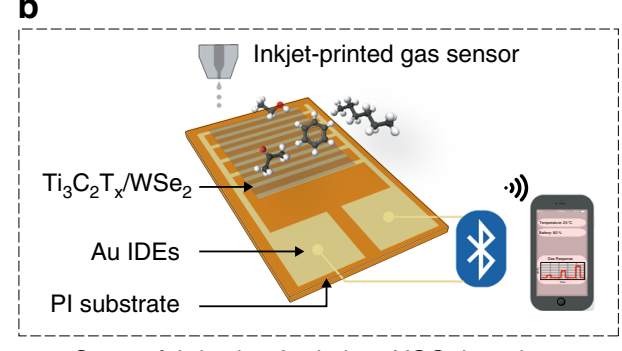

Sensor fabrication \& wireless VOC detections

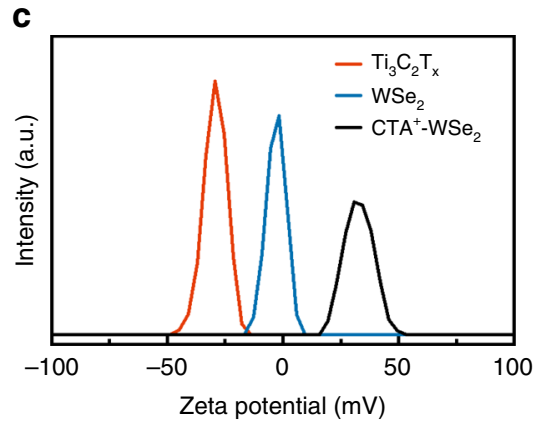

Fig. $1 \mathbf{T i}_{\mathbf{3}} \mathbf{C}_{\mathbf{2}} \mathbf{T}_{\mathbf{x}} / \mathbf{W S e _ { 2 }}$ hybridization and sensor fabrication. a Schematic illustration of preparation processes for $\mathrm{Ti}_{3} \mathrm{C}_{2} \mathrm{~T}_{\mathrm{x}} / \mathrm{WS} \mathrm{e}_{2}$ nanohybrids. $\mathbf{b} \mathrm{Schematic}$ illustration of inkjet-printed gas sensors in detection of volatile organic compounds with a wireless monitoring system. $\mathbf{c}$ Zeta potential distributions of $\mathrm{Ti}_{3} \mathrm{C}_{2} \mathrm{~T}_{\mathrm{x}}, \mathrm{WSe}_{2}$, and $\mathrm{CTA}+$-WSe 2 dispersions.

adsorb water and other molecules, which also add to the total thickness ${ }^{32}$. Indeed, the AFM height profile measured along the white line in Supplementary Fig. 4c shows that a representative $\mathrm{Ti}_{3} \mathrm{C}_{2} \mathrm{~T}_{\mathrm{x}}$ nanosheet has a thickness of $\sim 1.5 \mathrm{~nm}$, which can be regarded as MXene single layer ${ }^{33}$.

Microstructure analysis of $\mathrm{Ti}_{3} \mathrm{C}_{2} \mathrm{~T}_{\mathrm{x}} / \mathrm{WSe} \mathrm{C}_{2}$ nanohybrid. SEM imaging, as demonstrated in Fig. 2a, reveals that the as-printed $\mathrm{Ti}_{3} \mathrm{C}_{2} \mathrm{~T}_{\mathrm{x}} / \mathrm{WS} \mathrm{W}_{2}$ nanohybrids have a uniform surface morphology over a broad range of the samples area, in spite of the existence of a few pinholes. TEM imaging and diffraction analysis present further insight into the microstructures of the $\mathrm{Ti}_{3} \mathrm{C}_{2} \mathrm{~T}_{\mathrm{x}} / \mathrm{WSe} \mathrm{S}_{2}$ nanohybrids in Fig. 2b-d. TEM bright-field image (Fig. 2b) shows that $\mathrm{WSe}_{2}$ nanoflakes appear to disperse homogeneously on the $\mathrm{Ti}_{3} \mathrm{C}_{2} \mathrm{~T}_{\mathrm{x}}$ matrix. As $\mathrm{WSe}_{2}$ has a large atomic weight, a clear differentiable contrast in this bright-field micrograph is observed, with the darker $\mathrm{WSe}_{2}$ nanoflakes landed on the brighter $\mathrm{Ti}_{3} \mathrm{C}_{2} \mathrm{~T}_{\mathrm{x}}$ nanosheets. Such distribution is more obvious in higher magnification TEM image of a single $\mathrm{Ti}_{3} \mathrm{C}_{2} \mathrm{~T}_{\mathrm{x}} / \mathrm{WSe} \mathrm{S}_{2}$ nanohybrid in Fig. 2c, showing (a) uniform decoration of several even sized (typical $<30 \mathrm{~nm}$ ) WSe $e_{2}$ nanoflakes on the $\mathrm{Ti}_{3} \mathrm{C}_{2} \mathrm{~T}_{\mathrm{x}}$ scaffolds which have a typical size of $\sim 300 \mathrm{~nm}$ and (b) the hybridization process forming a numerous heterojunction interfaces that may benefits the gas-sensing performance. The dynamic light scattering measurements (Supplementary Fig. 5) indicate that $\mathrm{Ti}_{3} \mathrm{C}_{2} \mathrm{~T}_{\mathrm{x}} / \mathrm{WSe}_{2}$ nanohybrids exhibit an average particle size of $350 \pm 100 \mathrm{~nm}$, closely consistent with the TEM imaging analysis.

As demonstrated by the high-resolution TEM image in Fig. 2d, $\mathrm{WSe}_{2}$ nanoflakes with a lattice fringe of $0.28 \mathrm{~nm}$ were distributed on the edges of the $\mathrm{Ti}_{3} \mathrm{C}_{2} \mathrm{~T}_{\mathrm{x}}$ nanosheets, which corresponds to the (100) plane of hexagonal $\mathrm{WSe}_{2}{ }^{34}$. Moreover, the associated selected area electron diffraction pattern in Fig. 2e reveals various diffraction rings (denoted as $\mathrm{T}$ ), indexed as from the matrix of the hexagonal $\mathrm{Ti}_{3} \mathrm{C}_{2} \mathrm{~T}_{\mathrm{x}}$ nanosheets. Meanwhile, some diffraction spots (denoted as W) coexist with the continuous rings attributed to the adsorbed $\mathrm{WSe}_{2}$ nanoflakes. To investigate further the elemental distribution of the $\mathrm{Ti}_{3} \mathrm{C}_{2} \mathrm{~T}_{\mathrm{x}} / \mathrm{WSe} \mathrm{W}_{2}$ nanohybrid structure, high-angle annular dark-field-scanning transmission electron microscopy (HAADF-STEM) imaging and the energy-dispersive $\mathrm{X}$-Ray elemental mapping were carried out, and Fig. $2 \mathrm{f}$ presents a representative result, indicating a uniform distribution of $\mathrm{Ti}, \mathrm{W}$, and Se within the hybrid.

Chemical composition of $\mathrm{Ti}_{3} \mathrm{C}_{2} \mathrm{~T}_{\mathrm{x}} / \mathrm{WSe} \mathrm{e}_{2}$ nanohybrids. Figure $3 \mathrm{a}-\mathrm{d}$ shows a set of high-resolution XPS spectra (Ti 2p, O 1s, C 1s, and $\mathrm{W} 4 \mathrm{f}$ ) taken from $\mathrm{Ti}_{3} \mathrm{C}_{2} \mathrm{~T}_{\mathrm{x}} / \mathrm{WS} \mathrm{S}_{2}$ nanohybrids. Interpreting these spectra can identify the chemical structure of $\mathrm{WSe}_{2}$ nanoflakes and $\mathrm{Ti}_{3} \mathrm{C}_{2} \mathrm{~T}_{\mathrm{x}}$ nanosheets, as well as the successful fabrication of $\mathrm{Ti}_{3} \mathrm{C}_{2} \mathrm{~T}_{\mathrm{x}} / \mathrm{WSe}_{2}$ nanohybrids. The Ti $2 \mathrm{p}$ spectrum (Fig. 3a) was fitted with a fixed area ratio of 2:1 and a doublet separation of $5.8 \mathrm{eV}$ comprising four doublets ( $\mathrm{Ti} 2 \mathrm{p}_{3 / 2}$ and $\mathrm{Ti} 2 \mathrm{p}_{1 / 2}$ ). The binding energies of $\mathrm{Ti} 2 \mathrm{p}_{3 / 2}$ for $\mathrm{Ti}-\mathrm{C}, \mathrm{Ti}^{2+}, \mathrm{Ti}^{3+}$, and $\mathrm{Ti}-\mathrm{O}$ are $454.5,455.3,456.9$, and $458.9 \mathrm{eV}$, respectively, in agreement with previous XPS studies ${ }^{35-37}$. Herein, the fresh $\mathrm{Ti}_{3} \mathrm{C}_{2} \mathrm{~T}_{\mathrm{x}}$ scaffold was successfully fabricated and it was significantly different from the oxidized MXene where only $\mathrm{Ti}-\mathrm{O}$ peaks were observed (Supplementary Fig. 6$)^{37}$. The $O$ s spectrum in Fig. $3 \mathrm{~b}$ can be deconvoluted into four peaks centered at 530.9, 531.7, 532.6, and $533.6 \mathrm{eV}$, corresponding to surface species of $\mathrm{C}-\mathrm{Ti}-\mathrm{O}_{\mathrm{x}}, \mathrm{C}-\mathrm{Ti}$ $-\mathrm{OH}$, adsorbed oxygen and $\mathrm{H}_{2} \mathrm{O}$, respectively ${ }^{38,39}$. This finding confirms that the surface of the $\mathrm{Ti}_{3} \mathrm{C}_{2} \mathrm{~T}_{\mathrm{x}}$ nanosheet indeed is terminated by an abundance of functional groups, facilitating its hybridization with $\mathrm{WSe}_{2}$. The $\mathrm{C} 1 \mathrm{~s}$ spectrum in Fig. 3c was deconvoluted to four peaks centered at 281.7, 284.8, 286.3, and $288.6 \mathrm{eV}$, corresponding to $\mathrm{C}-\mathrm{Ti}, \mathrm{C}-\mathrm{C}, \mathrm{CH}_{\mathrm{x}} / \mathrm{CO}$ and $\mathrm{COO}$, respectively ${ }^{36}$. The existence of $\mathrm{WSe}_{2}$ nanosheets is also confirmed by the high-resolution XPS spectrum in Fig. 3d, which shows two main characteristic peaks of $\mathrm{W}^{4+}$ at $32.2 \mathrm{eV}\left(\mathrm{W}_{4 / 2}\right)$ and $34.3 \mathrm{eV}\left(\mathrm{W} 4 \mathrm{f}_{5 / 2}\right)$. 

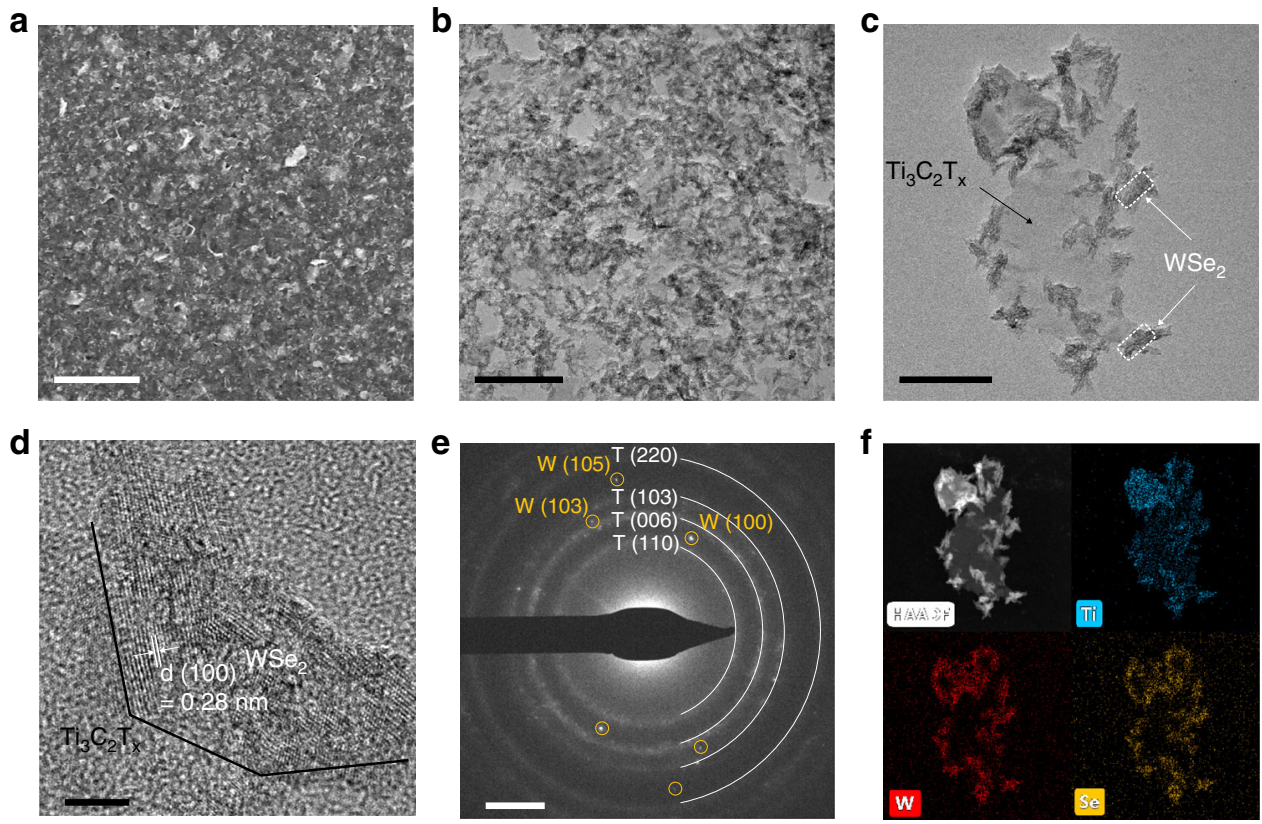

Fig. 2 Microstructure analysis of $\mathbf{T i}_{\mathbf{3}} \mathbf{C}_{\mathbf{2}} \mathbf{T}_{\mathbf{x}} / \mathbf{W S e} \mathbf{e}_{\mathbf{2}}$ nanohybrids. a SEM image of $2 \mathrm{D} \mathrm{Ti}{ }_{3} \mathrm{C}_{2} \mathrm{~T}_{x} / \mathrm{WSe} \mathrm{e}_{2}$ nanohybrid film (scale bar, $2 \mu \mathrm{m}$ ). $\mathbf{b} \mathrm{Low}$ magnification TEM image (scale bar, $200 \mathrm{~nm}$ ), with c showing image of a single $\mathrm{Ti}_{3} \mathrm{C}_{2} \mathrm{~T}_{x} / \mathrm{WSe}_{2}$ nanohybrid (scale bar, $100 \mathrm{~nm}$ ). d High-resolution TEM image of $\mathrm{Ti}_{3} \mathrm{C}_{2} \mathrm{~T}_{x} / \mathrm{WSe}_{2}$ nanohybrid (scale bar, $100 \mathrm{~nm}$ ). e Selected area electron diffraction pattern of $\mathrm{Ti}_{3} \mathrm{C}_{2} \mathrm{~T}_{x} / \mathrm{WSe}_{2}$ nanohybrids (scale bar, $2 \mathrm{~nm}{ }^{-1}$ ). $\mathbf{f} \mathrm{HAADF}-$ STEM image and corresponding elemental mapping of $\mathrm{Ti}, \mathrm{W}$, and $\mathrm{Se}$ for the $\mathrm{Ti}_{3} \mathrm{C}_{2} \mathrm{~T}_{\mathrm{x}} / \mathrm{WSe}_{2}$ nanohybrid showing a uniform decoration of WSe $\mathrm{e}_{2}$ nanoflakes on $\mathrm{Ti}_{3} \mathrm{C}_{2} \mathrm{~T}_{x}$ matrix.
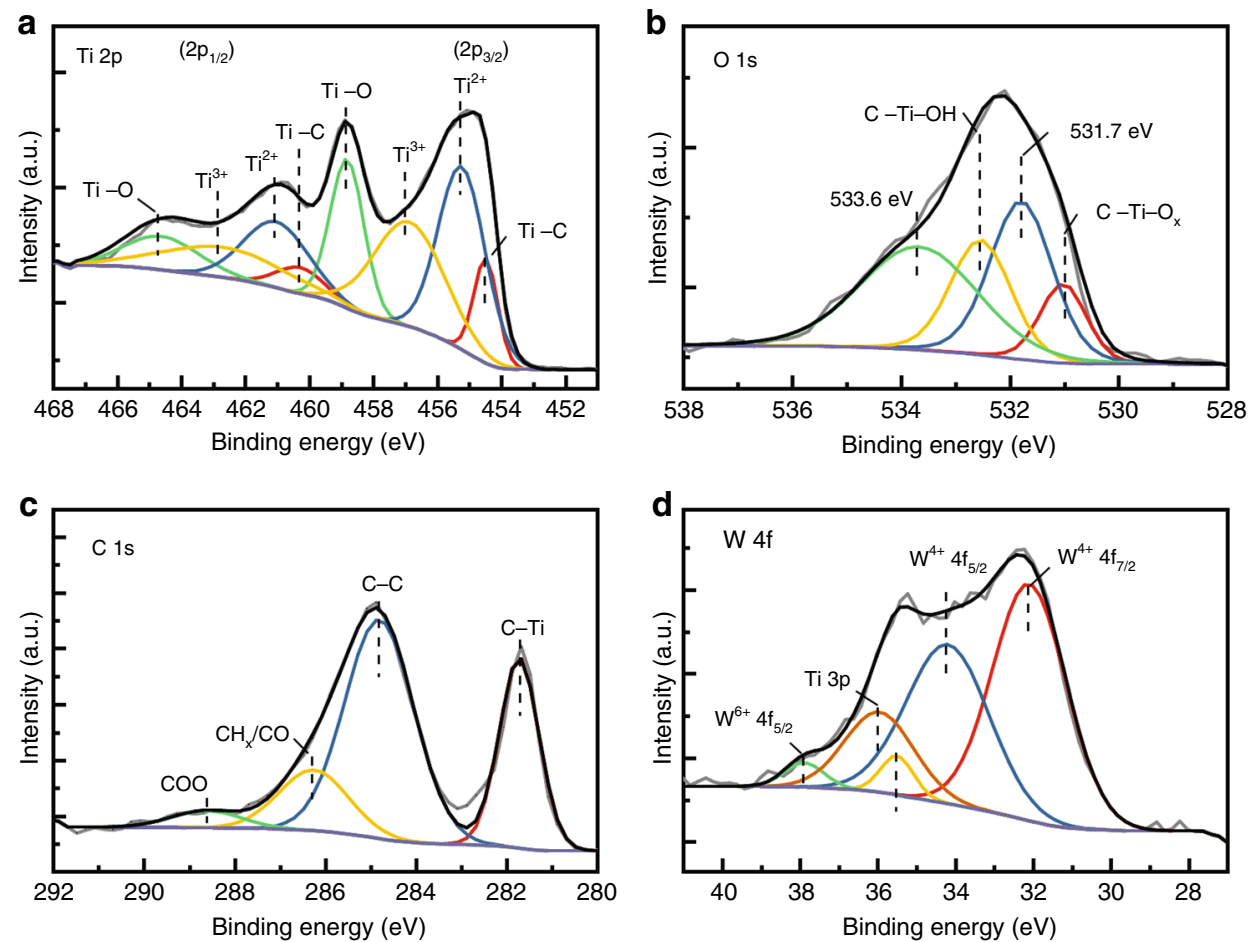

Fig. 3 Chemical composition of $\mathbf{T i}_{3} \mathbf{C}_{\mathbf{2}} \mathbf{T}_{\mathbf{x}} / \mathbf{W S e} \mathbf{2}_{\mathbf{2}}$ nanohybrids. High-resolution XPS spectra of a Ti $2 \mathrm{p}, \mathbf{b} O 1 \mathrm{~s}, \mathbf{c} \mathrm{C} 1 \mathrm{~s}$, and $\mathbf{d} \mathrm{W} 4 \mathrm{f}$ from Ti ${ }_{3} \mathrm{C}_{2} \mathrm{~T}_{x} / \mathrm{WSe} \mathrm{e}_{2}$ nanohybrids, showing chemical components and structures of $\mathrm{Ti}_{3} \mathrm{C}_{2} \mathrm{~T}_{x} / \mathrm{WSe}_{2}$ nanohybrids.

Gas-sensing performance of $\mathrm{WSe}_{2}$ decorated MXene sensors. The sensing performance of $\mathrm{Ti}_{3} \mathrm{C}_{2} \mathrm{~T}_{\mathrm{x}}$ decorated with various amounts of $\mathrm{WSe}_{2}$ (2 and $\left.4 \mathrm{wt} \%\right)$ toward 40 -ppm ethanol was first examined using individual $\mathrm{Ti}_{3} \mathrm{C}_{2} \mathrm{~T}_{\mathrm{x}}$ and $\mathrm{WSe}_{2}$ sensors as references. A detailed account of the results is presented in Supplementary Information (Supplementary Fig. 7a-d and
Supplementary Note 2). The response of both $\mathrm{Ti}_{3} \mathrm{C}_{2} \mathrm{~T}_{\mathrm{x}}$ and $\mathrm{WSe}_{2}$ sensors is inferior to that of $\mathrm{Ti}_{3} \mathrm{C}_{2} \mathrm{~T}_{\mathrm{x}}$ loaded with a moderate amount of $\mathrm{WSe}_{2}$ nanoflakes (2 wt\%), the latter showing the strongest and fastest response toward ethanol. It can be observed that the ethanol response decreases as the $\mathrm{WSe}_{2}$ loading increases from 2 to $4 \mathrm{wt} \%$, which is attributed to the excessive number of 
$\mathrm{WSe}_{2}$ nanoflakes blocking heterojunctions of $\mathrm{Ti}_{3} \mathrm{C}_{2} \mathrm{~T}_{\mathrm{x}} / \mathrm{WSe}_{2}$ hybrids (proposed as the major adsorption sites), as also observed from HAADF-STEM images (Supplementary Fig. 7f, g). Their electrical noise was further determined by measuring the response fluctuation during sensor exposure to air. The electrical noise levels of $\mathrm{WSe}_{2}, \mathrm{Ti}_{3} \mathrm{C}_{2} \mathrm{~T}_{\mathrm{x}}$, and $\mathrm{Ti}_{3} \mathrm{C}_{2} \mathrm{~T}_{\mathrm{x}} / \mathrm{WSe}_{2}(2 \mathrm{wt} \%)$ sensors were $\sim 1,0.08$, and $0.15 \%$, respectively; the high noise level registered for $\mathrm{WSe}_{2}$ limits its use for high-performance sensors and stems from its high electrical resistance. Moreover, sheet resistance $( \pm 1 \sigma ; N=3)$ of the pristine $\mathrm{WSe}_{2}$ films was $26.3 \pm 5.2$ $\mathrm{M} \Omega$ per square, while that of the $\mathrm{Ti}_{3} \mathrm{C}_{2} \mathrm{~T}_{\mathrm{x}}$ films loaded with $2 \mathrm{wt} \%$ $\mathrm{WSe}_{2}$ dramatically reduced to $3.3 \pm 0.5 \mathrm{k} \Omega$ per square; this is more than four orders of magnitude decrease in sheet resistance (equivalent increase in the electrical conductivity), owing to the hybridization of $\mathrm{WSe}_{2}$ with $\mathrm{Ti}_{3} \mathrm{C}_{2} \mathrm{~T}_{\mathrm{x}}$ with high metallic conductivity. Notably, the sensor based on $\mathrm{Ti}_{3} \mathrm{C}_{2} \mathrm{~T}_{\mathrm{x}} / \mathrm{WSe}_{2}$ nanohybrids not only exhibits the highest gas response, but also displays a low-electrical noise, further cementing the finding that the hybridization of MXenes to a TMD material yields superior VOC sensing performance in conductometric devices compared to individual MXene and TMD.

The thickness of sensing films deposited on electrodes in such devices is another key factor affecting performance ${ }^{40,41}$. Thus, gas-sensing performance of $\mathrm{Ti}_{3} \mathrm{C}_{2} \mathrm{~T}_{\mathrm{x}} / \mathrm{WSe}_{2}$ films with thicknesses of 60,120 , and $180 \mathrm{~nm}$ was examined by comparing their response curves toward the detection of 40-ppm ethanol and acetone (Supplementary Fig. 8). The response of the $\mathrm{Ti}_{3} \mathrm{C}_{2} \mathrm{~T}_{\mathrm{x}} /$ $\mathrm{WSe}_{2}$ sensors to both VOCs decreased dramatically with increasing film thickness; the ethanol response substantially decreased from $-9.2 \%$ to only $-0.7 \%$ as film thickness increased from $60 \mathrm{~nm}$ to $180 \mathrm{~nm}$. This is most likely because thickness increase of $\mathrm{Ti}_{3} \mathrm{C}_{2} \mathrm{~T}_{\mathrm{x}} / \mathrm{WSe}_{2}$ films lowers the surface-to-volume ratio of the $\mathrm{Ti}_{3} \mathrm{C}_{2} \mathrm{~T}_{\mathrm{x}} / \mathrm{WSe}_{2}$ channel, impeding gas uptake and transport within the film.

Hereafter, we have fabricated dozens of sensors made of 60-nm-thick $\mathrm{Ti}_{3} \mathrm{C}_{2} \mathrm{~T}_{\mathrm{x}} / \mathrm{WSe}_{2}$ electrode; three sensors were subjected to a variety of further sensing tests in parallel each run, using a $\mathrm{Ti}_{3} \mathrm{C}_{2} \mathrm{~T}_{\mathrm{x}}$ sensor as reference. The plots presented in Fig. 4 are typical of these measurements. Figure $4 \mathrm{a}$ presents sensing properties of pristine $\mathrm{Ti}_{3} \mathrm{C}_{2} \mathrm{~T}_{\mathrm{x}}$ and hybrid $\mathrm{Ti}_{3} \mathrm{C}_{2} \mathrm{~T}_{\mathrm{x}} / \mathrm{WSe}_{2}$ sensors upon exposure to ethanol vapors over a wide range of concentrations from 1 to $40 \mathrm{ppm}$. The $\mathrm{Ti}_{3} \mathrm{C}_{2} \mathrm{~T}_{\mathrm{x}}$ sensor shows a positive but relatively small increase of resistance to ethanol ( $\mathrm{p}$ type sensing behavior), indicating that the charge carrier transport channel is impeded by the adsorption of ethanol molecules. This positive response is ascribed to the metallic conductivity of $\mathrm{Ti}_{3} \mathrm{C}_{2} \mathrm{~T}_{\mathrm{x}}$, where gas adsorption reduces the number of charge carriers (electrons), resulting in an increase of channel resistance ${ }^{42}$. The unrecoverable response of the $\mathrm{Ti}_{3} \mathrm{C}_{2} \mathrm{~T}_{\mathrm{x}}$ sensor is observed by a slight upward drift of the baseline because of the incomplete gas desorption from $\mathrm{Ti}_{3} \mathrm{C}_{2} \mathrm{~T}_{\mathrm{x}}$ caused by chemisorption of ethanol ${ }^{43}$. Interestingly, the $\mathrm{Ti}_{3} \mathrm{C}_{2} \mathrm{~T}_{\mathrm{x}} /$ $\mathrm{WSe}_{2}$ sensor displays a negative variation of resistance in the presence of ethanol (n-type sensing behavior) in Fig. 4a, implying that the $\mathrm{Ti}_{3} \mathrm{C}_{2} \mathrm{~T}_{\mathrm{x}} / \mathrm{WSe}_{2}$ heterostructured sensor is dominated by different sensing mechanism compared to pristine $\mathrm{Ti}_{3} \mathrm{C}_{2} \mathrm{~T}_{\mathrm{x}}$. The responses of the $\mathrm{Ti}_{3} \mathrm{C}_{2} \mathrm{~T}_{\mathrm{x}}$ and $\mathrm{Ti}_{3} \mathrm{C}_{2} \mathrm{~T}_{\mathrm{x}} / \mathrm{WSe}_{2}$ sensors with concentration variations of ethanol are shown in Fig. 4b. Notably, standard deviations of the measured response values for the various ethanol concentrations were only $3.7 \%$ at most. Such small deviations suggest that the inkjet printing used here indeed offers high repeatability of electrode fabrication, thus giving low device-to-device variations. The response was almost linear and the sensitivity of the sensors here was calculated as the slope (response/ppm), showing a significant increase of sensitivity from 0.02 to 0.24 (12-fold) by the hybridization of $\mathrm{Ti}_{3} \mathrm{C}_{2} \mathrm{~T}_{\mathrm{x}}$ and $\mathrm{WSe}_{2}$.
The response of the $\mathrm{Ti}_{3} \mathrm{C}_{2} \mathrm{~T}_{\mathrm{x}} / \mathrm{WSe}_{2}$ sensor to ethanol does not reach a saturated state toward $40 \mathrm{ppm}$ of ethanol, indicating that the sensor has a strong ability to detect ethanol molecules over a wide range of concentrations. These enhancements are likely due to the formation of $\mathrm{Ti}_{3} \mathrm{C}_{2} \mathrm{~T}_{\mathrm{x}} / \mathrm{WSe}_{2}$ heterojunctions, providing not only fast electron transport but also acting as effective catalysts due to its appropriate chemical potential ${ }^{44}$. Thus, hybridizing $\mathrm{WSe}_{2}$ with $\mathrm{Ti}_{3} \mathrm{C}_{2} \mathrm{~T}_{\mathrm{x}}$ significantly enhances the gas-sensing performance and the detailed sensing mechanism will be discussed later in Fig. 5.

Figure $4 \mathrm{c}$ depicts the exposure of the $\mathrm{Ti}_{3} \mathrm{C}_{2} \mathrm{~T}_{\mathrm{x}} / \mathrm{WSe}_{2}$ sensor to 40-ppm ethanol for five consecutive cycles, demonstrating its repeatable, fast gas response and recovery. Moreover, the longterm stability of $\mathrm{Ti}_{3} \mathrm{C}_{2} \mathrm{~T}_{\mathrm{x}} / \mathrm{WSe}_{2}$ sensor was evaluated upon exposure to 40-ppm ethanol for a month at interval of 5 days (Fig. 4d). The response remained at around $-9.2 \%$ over a month period, indicating a good long-term stability of the $\mathrm{Ti}_{3} \mathrm{C}_{2} \mathrm{~T}_{\mathrm{x}} / \mathrm{WSe}_{2}$ sensor. This suggests that our hybridization process might also be an effective strategy to overcome the oxidation of MXenes 37,45 . Fig. $4 \mathrm{e}$ shows response/recovery properties of the $\mathrm{Ti}_{3} \mathrm{C}_{2} \mathrm{~T}_{\mathrm{x}} / \mathrm{WSe}_{2}$ sensor toward $40 \mathrm{ppm}$ of ethanol. The response time was defined as the time taken to reach $90 \%$ of the maximum gas response after the introduction of a VOC analyte. The recovery time was defined as the time taken to return to $10 \%$ of the minimum gas response after the removal of the target analyte. The $\mathrm{Ti}_{3} \mathrm{C}_{2} \mathrm{~T}_{\mathrm{x}} /$ $\mathrm{WSe}_{2}$ sensor demonstrated an ultrafast response $(9.7 \mathrm{~s})$ and recovery $(6.6 \mathrm{~s})$ at room temperature. The enhancement of gassensing performance could be attributed to the heterojunction formation that (a) effectively accelerates the transport of electrons and (b) serves as catalyst lowering the activation energy of gas analytes ${ }^{44,46}$.

To understand further the benefit of hybridizing $\mathrm{Ti}_{3} \mathrm{C}_{2} \mathrm{~T}_{\mathrm{x}}$ with $\mathrm{WSe}_{2}$ in the detection of various VOCs, the pristine $\mathrm{Ti}_{3} \mathrm{C}_{2} \mathrm{~T}_{\mathrm{x}}$ and $\mathrm{Ti}_{3} \mathrm{C}_{2} \mathrm{~T}_{\mathrm{x}} / \mathrm{WSe}_{2}$ sensors were exposed to $40 \mathrm{ppm}$ of various oxygen-containing VOCs: ethanol $\left(\mathrm{C}_{2} \mathrm{H}_{5} \mathrm{OH}\right)$, methanol $\left(\mathrm{CH}_{3} \mathrm{OH}\right)$, and acetone $\left(\mathrm{CH}_{3} \mathrm{COCH}_{3}\right)$ and carbon-based VOCs: hexane $\left(\mathrm{C}_{6} \mathrm{H}_{14}\right)$, benzene $\left(\mathrm{C}_{6} \mathrm{H}_{6}\right)$, and toluene $\left(\mathrm{C}_{6} \mathrm{H}_{5} \mathrm{CH}_{3}\right)$; their response values are presented in Fig. $4 \mathrm{f}$. For each of the individual target analytes, the $\mathrm{Ti}_{3} \mathrm{C}_{2} \mathrm{~T}_{\mathrm{x}}$ sensor shows a positive, smaller response value, while the $\mathrm{Ti}_{3} \mathrm{C}_{2} \mathrm{~T}_{\mathrm{x}} / \mathrm{WSe}_{2}$ sensor shows a negative and much higher response value. In general, the carbon-based molecules' (benzene, toluene and hexane) interaction with sensing surfaces is minimal, which results in a relatively small resistance variation for both sensors. Both $\mathrm{Ti}_{3} \mathrm{C}_{2} \mathrm{~T}_{\mathrm{x}}$ and $\mathrm{Ti}_{3} \mathrm{C}_{2} \mathrm{~T}_{\mathrm{x}} /$ $\mathrm{WSe}_{2}$ sensors exhibit a slightly higher response to toluene and hexane, as compared to benzene, owing to the presence of their methyl groups, which induces dipole scattering ${ }^{47}$. On the other hand, the $\mathrm{Ti}_{3} \mathrm{C}_{2} \mathrm{~T}_{\mathrm{x}} / \mathrm{WSe}_{2}$ sensor exhibits an enhancement in terms of selectivity and sensitivity toward the sensing of oxygencontaining molecules (ethanol, methanol, and acetone). The sensing behavior of $\mathrm{Ti}_{3} \mathrm{C}_{2} \mathrm{~T}_{\mathrm{x}} / \mathrm{WSe}_{2}$ hybrid sensor to oxygencontaining molecules is rather complicated and has not been well explored.

Environmental and mechanical stability of $\mathrm{Ti}_{3} \mathrm{C}_{2} \mathrm{~T}_{\mathrm{x}}$-based sensors. A serious challenge for $\mathrm{Ti}_{3} \mathrm{C}_{2} \mathrm{~T}_{\mathrm{x}}$ nanosheets being used as functional coatings or truly useful device materials is their high susceptibility to environmental degradation under humid atmosphere or in aqueous solution $33,48,49$. We hypothesize that hybridization with $\mathrm{WSe}_{2}$ could help overcome this challenge. To test this hypothesis, we selected water vapor over a wide range of relative humidity (RH) from 5 to $80 \%$ as an interference component and tested the environmental stability of the hybrid $\mathrm{Ti}_{3} \mathrm{C}_{2} \mathrm{~T}_{\mathrm{x}} / \mathrm{WSe}_{2}$ film using pristine $\mathrm{Ti}_{3} \mathrm{C}_{2} \mathrm{~T}_{\mathrm{x}}$ film as a control. A full account of results is presented in Fig. $5 \mathrm{a}-\mathrm{d}$. Figure $5 \mathrm{a}$ shows 


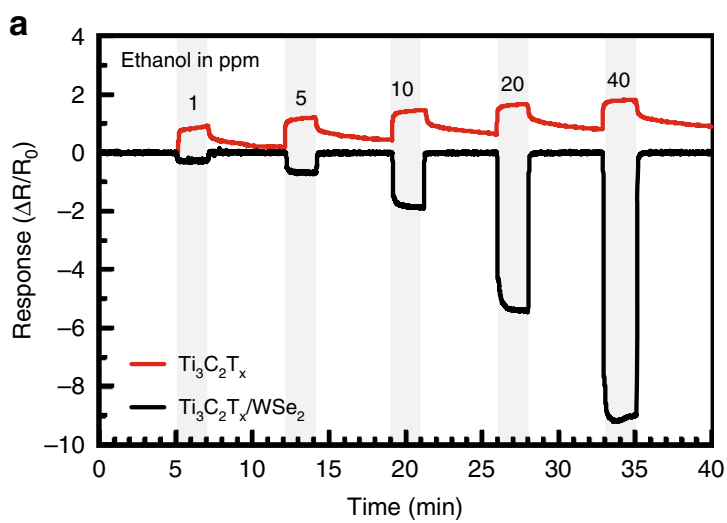

b
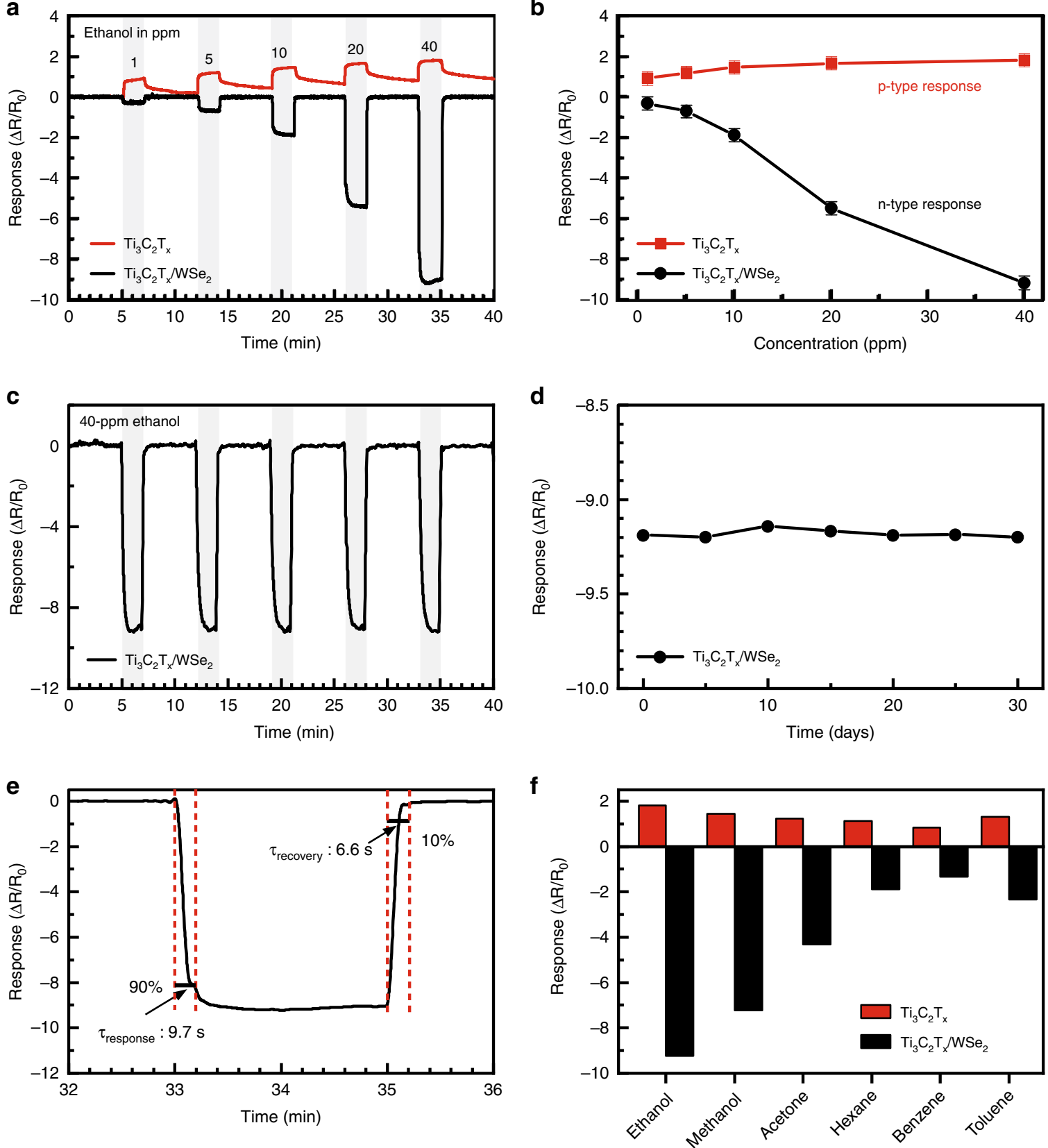

Fig. 4 Sensing characteristics of MXene-based VOC sensors. a Real-time sensing response of $\mathrm{Ti}_{3} \mathrm{C}_{2} \mathrm{~T}_{x}$ and $\mathrm{Ti}_{3} \mathrm{C}_{2} \mathrm{~T}_{x} /$ WSe $e_{2}$ gas sensors upon ethanol exposure with concentrations ranging from 1 to $40 \mathrm{ppm}$. $\mathbf{b}$ Comparison of gas response as a function of ethanol gas concentrations for $\mathrm{Ti}_{3} \mathrm{C}_{2} \mathrm{~T}_{\mathrm{x}}$ and $\mathrm{Ti}_{3} \mathrm{C}_{2} \mathrm{~T}_{x} / \mathrm{WS}_{2}$ sensors. c Cycling performance of $\mathrm{Ti}_{3} \mathrm{C}_{2} \mathrm{~T}_{x} / \mathrm{WS} \mathrm{e}_{2}$ gas sensors in response to ethanol at 40 ppm level. $\mathbf{d}$ Long-term stability of response over a month under $40 \mathrm{ppm}$ of ethanol for $\mathrm{Ti}_{3} \mathrm{C}_{2} \mathrm{~T}_{x} / \mathrm{WSe}_{2}$ sensor. e Response and recovery times calculated for 40 ppm of ethanol. $\mathbf{f}$ Selectivity test of the $\mathrm{Ti}_{3} \mathrm{C}_{2} \mathrm{~T}_{\mathrm{x}}$ and $\mathrm{Ti}_{3} \mathrm{C}_{2} \mathrm{~T}_{\mathrm{x}} / \mathrm{WS} \mathrm{S}_{2}$ sensors upon exposure to various $\mathrm{VOCs}$ at $40 \mathrm{ppm}$.

small changes in electrical conductance of $\mathrm{Ti}_{3} \mathrm{C}_{2} \mathrm{~T}_{\mathrm{x}}$ and $\mathrm{Ti}_{3} \mathrm{C}_{2} \mathrm{~T}_{\mathrm{x}} /$ $\mathrm{WSe}_{2}$ films under low humidity (5\%) over a period of 10 days, indicating that both films are quite stable in the dry environment. However, after storage in the humid environment with alternative RHs of 5 and $80 \%$ over 10 days, electrical conductance of the $\mathrm{Ti}_{3} \mathrm{C}_{2} \mathrm{~T}_{\mathrm{x}}$ dramatically decreased to $21 \%$ of its original value; by contrast, the $\mathrm{Ti}_{3} \mathrm{C}_{2} \mathrm{~T}_{\mathrm{x}} / \mathrm{WSe}_{2}$ remained $88 \%$ of initial conductance after exposure to $80 \%$ of $\mathrm{RH}$, and recovered to $92 \%$ in dry environment (Fig. 5b).

To evaluate the effect of humidity levels on gas-sensing performance of the hybrid $\mathrm{Ti}_{3} \mathrm{C}_{2} \mathrm{~T}_{\mathrm{x}} / \mathrm{WSe}_{2}$ sensor, we measured its response to $40 \mathrm{ppm}$ of ethanol under various $\mathrm{RH}$ levels from 5 to $80 \%$. As revealed by Fig. $5 c$, d, the response of the $\mathrm{Ti}_{3} \mathrm{C}_{2} \mathrm{~T}_{\mathrm{x}} / \mathrm{WSe} \mathrm{S}_{2}$ sensor changes from -12 to $-6.1 \%$ as the humidity level increases from 5 to $80 \%$, indicating that although there is a humidity effect, the hybrid sensor is still functioning well in high humidity environment. The decrease in response is attributed to partial occupancy of water molecules on the sensing sites, causing a decrease in sensing performance ${ }^{50}$. The results suggest that MXenes indeed tend to oxidize in a humid environment, but adequate loading of TMD nanoflakes to edges of MXene nanosheets provides an effective strategy to block the direct interaction of $\mathrm{H}_{2} \mathrm{O}$ with MXenes, which thus is an approach to promoting MXene materials for real-life applications.

The stability of conductance and sensing response of the fully inkjet-printed flexible $\mathrm{Ti}_{3} \mathrm{C}_{2} \mathrm{~T}_{\mathrm{x}} / \mathrm{WSe} \mathrm{S}_{2}$ (wireless) sensor against 

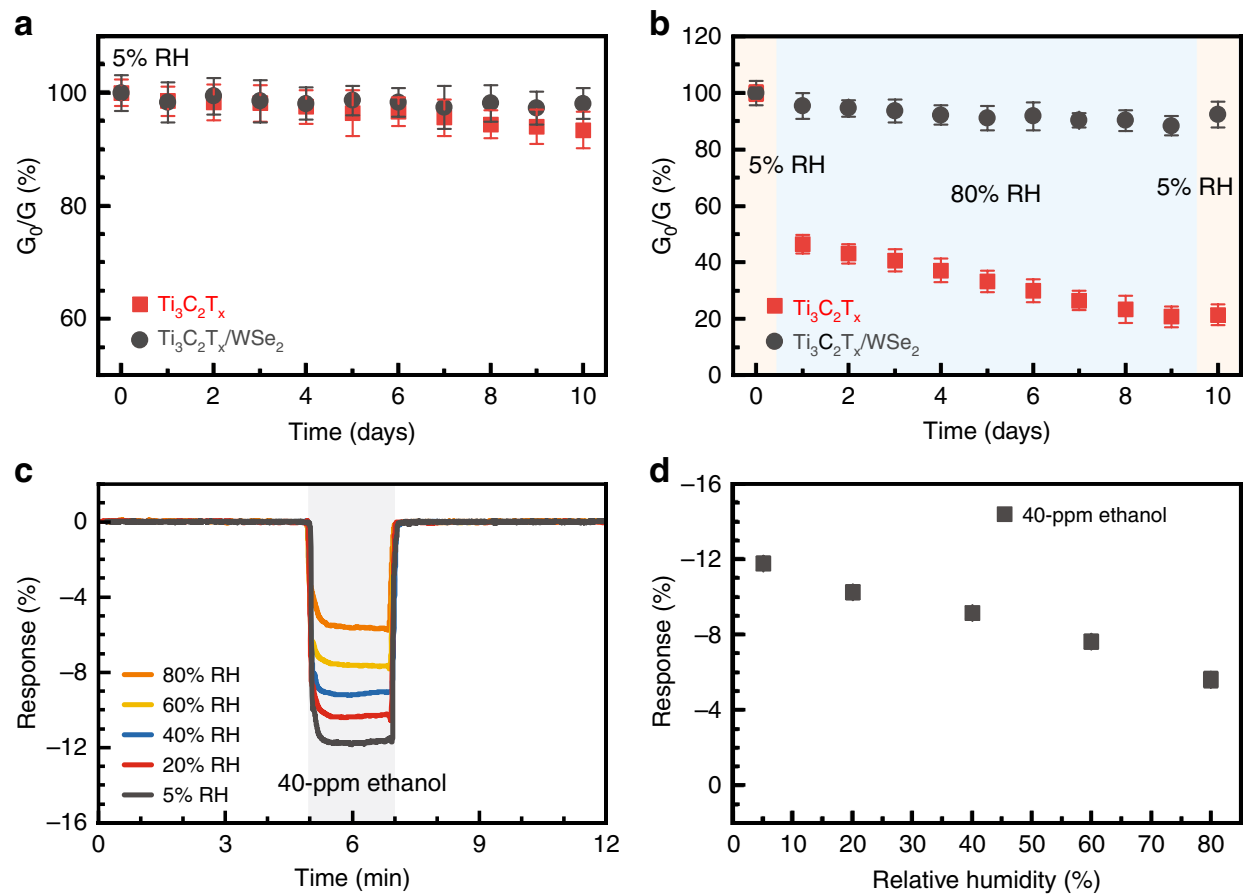

Fig. 5 Environmental stability of $\mathbf{T i}_{3} \mathbf{C}_{\mathbf{2}} \mathbf{T}_{\mathbf{x}}$ and hybrid $\mathbf{T i}_{3} \mathbf{C}_{\mathbf{2}} \mathbf{T}_{\mathbf{x}} / \mathbf{W S e} \mathbf{e}_{\mathbf{2}}$ films. Changes in electrical conductance of pristine $\mathrm{Ti}_{3} \mathrm{C}_{2} \mathrm{~T}_{x}$ and hybrid $\mathrm{Ti}_{3} \mathrm{C}_{2} \mathrm{~T}_{x} / \mathrm{WS} \mathrm{e}_{2}$ sensors under $\mathbf{a} 5 \% \mathrm{RH}$ and $\mathbf{b}$ alternative RHs of 5 and $80 \%$ over 10 days. $\mathbf{c}$ Evolution of responses of $\mathrm{Ti}_{3} \mathrm{C}_{2} \mathrm{~T}_{x} / \mathrm{WSe}_{2}$ sensors to 40 ppm of ethanol under various $\mathrm{RH}$ and $\mathbf{d}$ the sensing responses as a function of $\mathrm{RHs}$ from 5 to $80 \%$.
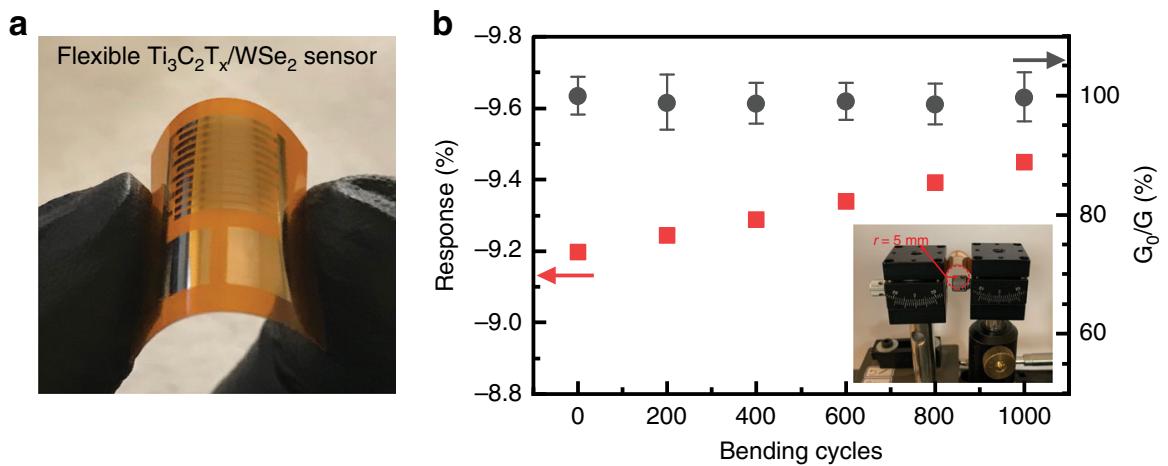

Fig. 6 Mechanical stability of hybrid $\mathbf{T i}_{3} \mathbf{C}_{\mathbf{2}} \mathbf{T}_{\mathbf{x}} / \mathbf{W S} \mathbf{S}_{\mathbf{2}}$ films. a Photograph of a flexible $\mathrm{Ti}_{3} \mathrm{C}_{2} \mathrm{~T}_{x} / \mathrm{WS} \mathrm{e}_{2}$ nanohybrid sensor. $\mathbf{b}$ Changes in ethanol sensing response and electrical conductance as a function of bending cycles.

mechanical bending was also investigated demonstrating its potential application to IoTs, using ethanol as a target analyte. Figure 6a displays a photograph of the flexible gas sensor. As shown in Fig. 6b, even after 1000 cycles of a bending test with a bending radius of $5 \mathrm{~mm}$, the response of the sensor to $40 \mathrm{ppm}$ of ethanol does not decay; instead, it increased slightly probably due to the creation of bending-induced reactive sensing sites, such as microcracks and wrinkles by the strain force ${ }^{34}$. Moreover, the electrical conductance of the sensor was rather stable even after 1000 bending cycles (Fig. 6b), indicating good flexibility and high mechanical strength of the $\mathrm{Ti}_{3} \mathrm{C}_{2} \mathrm{~T}_{\mathrm{x}} / \mathrm{WSe} \mathrm{S}_{2}$ sensor. The retaining of the conductance level on the baseline of the sensor suggests that prolonged bending does not have a negative impact on the sensing properties of the $\mathrm{Ti}_{3} \mathrm{C}_{2} \mathrm{~T}_{\mathrm{x}} / \mathrm{WSe} \mathrm{S}_{2}$ sensor.

Enhanced sensing mechanism for $\mathrm{Ti}_{3} \mathrm{C}_{2} \mathrm{~T}_{\mathrm{x}} / \mathrm{WSe} \mathrm{e}_{2}$ nanohybrids. Herein, we propose a sensing mechanism for the enhanced oxygen-based VOCs detection with $\mathrm{Ti}_{3} \mathrm{C}_{2} \mathrm{~T}_{\mathrm{x}} / \mathrm{WS} \mathrm{H}_{2}$ nanohybrids.
As shown in Fig. 7a, the band structure of $\mathrm{Ti}_{3} \mathrm{C}_{2} \mathrm{~T}_{\mathrm{x}} / \mathrm{WSe} \mathrm{e}_{2}$ nanohybrids, with a partially occupied band crossing the Fermi level, offers a good catalytic effect for enhancements of sensing reactions because the highly conductive $\mathrm{Ti}_{3} \mathrm{C}_{2} \mathrm{~T}_{\mathrm{x}}$ nanosheets readily supplies a flow of electrons to $\mathrm{WSe}_{2}{ }^{44}$. In fresh air, the electrons were trapped by adsorbed oxygen species $\left(\mathrm{O}_{2}{ }^{-}\right.$and $\left.\mathrm{O}^{-}\right)$owing to its electron-deficient nature, thus creating a depletion layer. Upon exposure to oxygen-based VOCs (Fig. 7b), the adsorbed active oxygen species react with ethanol molecules subsequently forming volatile gases $\left(\mathrm{CO}_{2}\right.$ and $\left.\mathrm{H}_{2} \mathrm{O}\right)$ and releasing electrons back to the conduction band, thereby resulting in a reduction in the depletion layer and resistance of the sensor (n-type sensing behavior in $\mathrm{Ti}_{3} \mathrm{C}_{2} \mathrm{~T}_{\mathrm{x}} / \mathrm{WSe} \mathrm{S}_{2}$ channels). Notably, $\mathrm{Ti}_{3} \mathrm{C}_{2} \mathrm{~T}_{\mathrm{x}} / \mathrm{WSe}_{2}$ nanohybrids significantly increase adsorbed oxygen species (in turn trap more electrons) because of the numerous heterojunction interfaces formed (as shown from TEM imaging), resulting in a large number of captured electrons released back to the $\mathrm{Ti}_{3} \mathrm{C}_{2} \mathrm{~T}_{\mathrm{x}} / \mathrm{WSe} \mathrm{S}_{2}$ channel and thus significantly improving the 
a

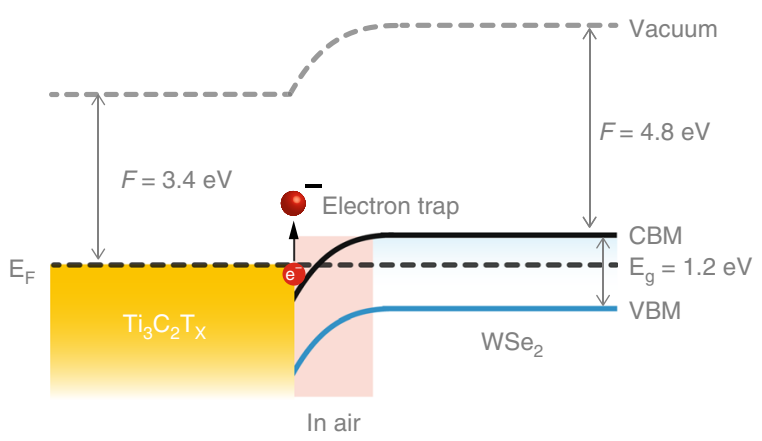

In air b

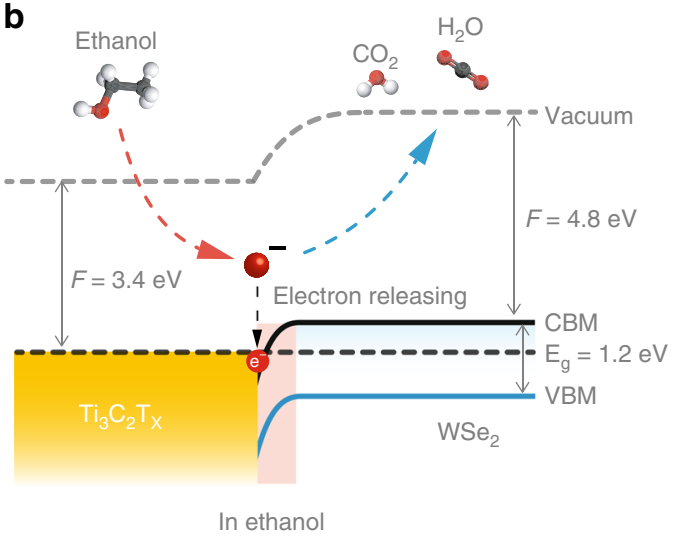

: adsorbed oxygen

Fig. 7 Enhanced sensing mechanism of $\mathbf{T i}_{3} \mathbf{C}_{\mathbf{2}} \mathbf{T}_{\mathbf{x}} / \mathbf{W S} \mathbf{e}_{\mathbf{2}}$ heterostructure. Energy-band diagram of the $\mathrm{Ti}_{3} \mathrm{C}_{2} \mathrm{~T}_{x} / \mathrm{WSe} \mathrm{e}_{2}$ in $\mathbf{a}$ air and $\mathbf{b}$ ethanol, showing the variation of the depletion layer with interaction between adsorbed oxygen species and ethanol molecules.

sensing response and selectivity in detection of oxygen-containing VOCs.

A variety of strategies have been conducted to enhance the gassensing performance of $2 \mathrm{D} \mathrm{TMD}$, including incorporation of metallic nanoparticles, semiconducting metal oxides, conducting polymers or carbon-based materials ${ }^{20-24}$. The $\mathrm{Ti}_{3} \mathrm{C}_{2} \mathrm{~T}_{\mathrm{x}} / \mathrm{WSe}_{2}$ heterostructured sensors examined here are compared with other representative 2D TMD-based hybrid sensors listed in Supplementary Table 2. Our integration of the solution processing method in the synthesis of a gas-sensing material, namely $\mathrm{Ti}_{3} \mathrm{C}_{2} \mathrm{~T}_{\mathrm{x}} / \mathrm{WSe}_{2}$ nanohybrid, was successful toward the fabrication of flexible VOC sensors using inkjet printing. Importantly, the $\mathrm{Ti}_{3} \mathrm{C}_{2} \mathrm{~T}_{\mathrm{x}} / \mathrm{WSe}_{2}$ sensors reported herein show either a lower detection limit than most other ethanol sensors, or a higher sensitivity at room temperature. Moreover, we demonstrated ultrafast response/recovery properties, which were not reported in most other publications on the detection of ethanol. In addition, the low-electrical-noise $\mathrm{Ti}_{3} \mathrm{C}_{2} \mathrm{~T}_{\mathrm{x}} / \mathrm{WSe}_{2}$ nanohybrid offers exceptional stability and durability against prolonged mechanical bending and environmental testing, along with the manufacturability of a sensor platform demonstrated, offer a unique opportunity for real-sensing applications to IoTs. For example, the high electrical noise values demonstrated by individual transition metal dichalcogenide materials limit the actual use of such sensors even when laboratory-based performance is adequate. The integration of MXene/TMD hybrid sensors with the features of Bluetooth wireless communication, flexibility and durability shed light on the development of next-generation fielddeployable sensor devices suitable for IoT applications.

\section{Discussion}

We have reported $\mathrm{Ti}_{3} \mathrm{C}_{2} \mathrm{~T}_{\mathrm{x}} / \mathrm{WSe}_{2}$ nanohybrids, fabricated through a facile surface-treating and exfoliation-based process, as sensing materials incorporated in an inkjet-printing and wirelessly-operating sensor for the detection of a variety of VOCs at room temperature. Inkjet printing offers repeatable fabrication of $\mathrm{Ti}_{3} \mathrm{C}_{2} \mathrm{~T}_{\mathrm{x}} / \mathrm{WSe}_{2}$ sensors, thus giving low device-todevice variations and reproducibility of the sensing measurements. Compared with the sensors made of pristine $\mathrm{Ti}_{3} \mathrm{C}_{2} \mathrm{~T}_{\mathrm{x}}$ and pristine $\mathrm{WSe}_{2}$, the $\mathrm{Ti}_{3} \mathrm{C}_{2} \mathrm{~T}_{\mathrm{x}} / \mathrm{WSe}_{2}$ hybrid sensor exhibits a 12fold increase in ethanol sensitivity, low-electrical noise, sound selectivity, and ultrafast response/recovery properties. Moreover, this study sheds light on the hybridization of MXenes with TMDs as sensing materials overcoming the notorious instability and oxidization tendency of individual MXenes, which thus is an approach to promoting MXene materials for real-life applications. The enhancement of the sensing performance to oxygencontaining VOCs is likely due to the numerous heterojunction interfaces formed by $\mathrm{Ti}_{3} \mathrm{C}_{2} \mathrm{~T}_{\mathrm{x}} / \mathrm{WSe}_{2}$ nanohybrids and its sensing mechanism is proposed. Thus, the flexible sensors reported here have a high potential for use as practical gas-sensing devices for IoTs. We anticipate that the hybridizing approach of this work would be extended to other 2D MXene materials for sensing applications.

\section{Methods}

Preparation of $\mathrm{Ti}_{3} \mathrm{C}_{2} \mathrm{~T}_{\mathrm{x}}$ nanosheets, WSe $\mathrm{W}_{2}$ nanoflakes, and $\mathrm{Ti}_{3} \mathrm{C}_{\mathbf{2}} \mathrm{T}_{\mathrm{x}} / \mathrm{WSe} \mathrm{e}_{2}$ inks. A total of $5 \mathrm{~g}$ of $\mathrm{Ti}_{3} \mathrm{AlC}_{2}$ powders (particle size $<40 \mu \mathrm{m}$, Carbon-Ukraine Ltd.) were etched in $100 \mathrm{~mL}$ of hydrofluoric (30\%) aqueous solution and stirred for $24 \mathrm{~h}$ at room temperature to remove $\mathrm{Al}$ atoms from the $\mathrm{Ti}_{3} \mathrm{AlC}_{2}$ powders, Then, the $\mathrm{Ti}_{3} \mathrm{C}_{2} \mathrm{~T}_{\mathrm{x}}$ powders were washed via centrifugation several times with deionized water until the $\mathrm{pH}$ value of the supernatant reached around 6 . The sediment was collected and rewashed with deionized water by vacuum filtration using difluoride membrane with $0.22 \mu \mathrm{m}$ pore size (Durapore, Millipore), subsequently dried in a vacuum oven at $60^{\circ} \mathrm{C}$ for $8 \mathrm{~h}$. The fabrication of $\mathrm{Ti}_{3} \mathrm{C}_{2} \mathrm{~T}_{\mathrm{x}}$ nanosheets was performed by sonicating $200 \mathrm{mg}$ of $\mathrm{Ti}_{3} \mathrm{C}_{2} \mathrm{~T}_{\mathrm{x}}$ powders in $50 \mathrm{~mL}$ of deionized water with ultrasonic bath (Branson, CPX2800H) for $1 \mathrm{~h}$, and centrifuged at $3500 \mathrm{rpm}$ for $1 \mathrm{~h}$ to separate the $\mathrm{Ti}_{3} \mathrm{C}_{2} \mathrm{~T}_{\mathrm{x}}$ layers. To avoid restacking of the nanosheets caused by the thermal energy released during sonication processing, the bath temperature was controlled at $4{ }^{\circ} \mathrm{C}$. The supernatant containing delaminated $\mathrm{Ti}_{3} \mathrm{C}_{2} \mathrm{~T}_{\mathrm{x}}$ nanosheets was collected for further hybridization. The concentration of $\mathrm{Ti}_{3} \mathrm{C}_{2} \mathrm{~T}_{\mathrm{x}}$ dispersion was measured by vacuum filtering the colloidal solution $\left(5.1 \pm 0.1 \mathrm{mg} \mathrm{mL}^{-1}\right)$. A total of $200 \mathrm{mg}$ of $\mathrm{WSe}_{2}$ powders ( $99 \%$ purity) from Sigma-Aldrich were dispersed in $20 \mathrm{~mL}$ of $1 \%$ cetyltrimethylammonium bromide (CTAB) aqueous solution followed by sonication at $4{ }^{\circ} \mathrm{C}$ for $10 \mathrm{~h}$ in an ultrasonic bath. As proven by zeta potential measurements, this treatment results in the adsorption of $\mathrm{CTA}^{+}$cations onto $\mathrm{WSe}_{2}$ nanoflakes. The functionalized dispersion was sequentially centrifuged at $2000 \mathrm{rpm}$ and $5000 \mathrm{rpm}$, which narrowed down the size distribution ${ }^{51}$. The supernatant containing CTA ${ }^{+}-\mathrm{WSe}_{2}$ nanoflakes $\left(1.3 \pm 0.1 \mathrm{mg} \mathrm{mL}^{-1}\right)$ was collected for further reaction. A total of $10 \mathrm{~mL}$ of $\mathrm{Ti}_{3} \mathrm{C}_{2} \mathrm{~T}_{\mathrm{x}}$ (as the hosting matrix of the nanohybrid) aqueous solution were added into $\mathrm{CTA}^{+}-\mathrm{WSe}_{2}$ solution at $60^{\circ} \mathrm{C}$ and stirred for $2 \mathrm{~h}$ to form a $\mathrm{Ti}_{3} \mathrm{C}_{2} \mathrm{~T}_{\mathrm{x}} / \mathrm{WS} \mathrm{e}_{2}$ hybrid by electrostatic interaction. $\mathrm{Ti}_{3} \mathrm{C}_{2} \mathrm{~T}_{\mathrm{x}}$, WSe $e_{2}$, and $\mathrm{Ti}_{3} \mathrm{C}_{2} \mathrm{~T}_{\mathrm{x}}$ nanosheets mixed with 2 and $4 \mathrm{wt} \%$ of $\mathrm{WSe}_{2}$ nanoflakes were prepared for sensing performance evaluation. Glycerol was then added to the dispersions with an optimum weight ratio of 1:3, achieving a required viscosity for inkjet printing, which was typically around $10 \mathrm{cP}^{52}$.

Fabrication of inkjet-printed $\mathbf{T i}_{\mathbf{3}} \mathbf{C}_{\mathbf{2}} \mathbf{T}_{\mathbf{x}} / \mathbf{W S} \mathbf{S}_{\mathbf{2}}$ sensors. Nanogold ink (UTDAu40) from UT Dots, Inc. was printed by a commercial Dimatix DMP-2850 inkjet printer on polyimide substrates containing six pairs of gold interdigitated electrodes (IDEs) with a total active electrode area of $8 \mathrm{~mm} \times 8 \mathrm{~mm}$. Sensing layers of $\mathrm{Ti}_{3} \mathrm{C}_{2} \mathrm{~T}_{\mathrm{x}}, \mathrm{WSe} \mathrm{S}_{2}$ (as references) and $\mathrm{Ti}_{3} \mathrm{C}_{2} \mathrm{~T}_{\mathrm{x}} / \mathrm{WS} \mathrm{S}_{2}$ were printed, respectively, on the electrode surface of the flexible substrates, which were placed on a vacuum-heated platen and kept at $60^{\circ} \mathrm{C}$ to achieve a stable drying rate.

Characterization and gas-sensing measurements. Surface morphology and crystallinity of the $\mathrm{Ti}_{3} \mathrm{C}_{2} \mathrm{~T}_{\mathrm{x}} / \mathrm{WS} \mathrm{W}_{2}$ nanohybrids were examined by scanning electron 
microscopy (SEM; S-4800, Hitachi), transmission electron microscopy (TEM), high-angle annular dark-field scanning transmission electron microscopy (HAADF-STEM; Talos 200x, FEI), and X-ray diffractometry (XRD; X'Pert Pro, Panalytical) operated at $45 \mathrm{kV}$ and $40 \mathrm{~mA}$ using $\mathrm{Cu} \mathrm{K}_{\alpha}$. X-ray photoelectron spectroscopy (XPS; PHI 5000 Versaprobe, ULVAC-PHI) was used to investigate the chemical components and chemical bonding structures of the $\mathrm{Ti}_{3} \mathrm{C}_{2} \mathrm{~T}_{\mathrm{x}} / \mathrm{WSe}_{2}$ nanohybrids. Atomic force microscopy (AFM; Dimension 3100, Veeco) was used in tapping mode to measure film thickness and the profile of the nanosheets. Electrical sheet resistance of the films was measured using a Jandel four-point probe system. The measurements were taken from four different spots on the sample surface and the average values were presented. Dynamic light scattering (Zetasizer Nano ZS, Malvern Instruments) was used to examine the zeta potential and particle size distribution of the materials in aqueous solutions.

Gas-sensing measurements were performed in a homemade sensor testing system (Supplementary Note 1, Supplementary Fig. 3, and Supplementary Table 1) ${ }^{53}$. Briefly, the sensors were placed in a Teflon chamber with gas inlet and outlet pipelines. Mass flow controllers (5850E, Brooks Instruments) were used to control the concentrations of VOC analytes, by adjusting the flow rates of VOC analytes and dilution gas (dry air), with a total flow rate fixed at $500 \mathrm{ml} / \mathrm{min}$. The bubbler containing VOC analytes was set at a controlled temperature to maintain a stable vapor pressure. The gas concentrations were calibrated with a commercial VOC sensor (Honeywell, ToxiRAE Pro PID). Humidity interference tests were performed by introducing a VOC analyte gas into saturated salt solution and the relative humidity $(\mathrm{RH})$ was monitored with a commercially available humidity sensor (HDC 2010, Texas Instruments).

The response of the sensor is defined as:

$$
\text { Response }(\%)=\frac{R_{g}-R_{0}}{R_{0}} \times 100 \%=\frac{\Delta R}{R_{0}} \times 100 \%
$$

where $R_{g}$ and $R_{0}$ represent electrical resistances of the sensors in the presence of VOC analytes and dry air, respectively.

Wireless gas-sensing system. Electrical signals of the gas sensor were detected by a wireless reading system, and the corresponding functional block diagram and photographic image of the flexible sensor system (connected to the wireless reading system) are displayed in Supplementary Fig. 2. The wireless reading system consists of a wireless transceiver (nRF52832 SoC), a dual readout interface, analog-to-digital converter (ADC; NAU7802), and a highly accurate humidity/temperature sensor (HDC2010) from Texas Instruments. The transceiver features an ultralow-power 32-bit ARM Cortex-M4F microprocessor with a built-in radio that operates in the $2.4 \mathrm{GHz}$ ISM band, and $512 \mathrm{kB}$ flash memory for data logging when the sensor is disconnected from the network. Instant variations of the signals from gas sensors are detected by the analog-to-digital converter and converted to corresponding digital signals by the microprocessor such that they are wirelessly transmitted to a mobile device through the Bluetooth Low Energy (BLE). The dual readout interface was implemented by a 2-to-1 analog multiplexer that connects into a Wheatstone bridge with a digital potentiometer controlled by the microprocessor via $\mathrm{I}^{2} \mathrm{C}$ bus. During operation, the digital potentiometer is adjusted based on the ADC reading to match the resistance of the sensor as close as possible. This readout interface supports dual input with extreme high precision and minimal power consumption. The system is powered by a coin cell battery (cr2032).

\section{Data availability}

The data that support the findings of this study are available from the corresponding author upon reasonable request.

Received: 30 October 2019; Accepted: 14 February 2020;

Published online: 10 March 2020

\section{References}

1. Swan, M. Sensor mania! the Internet of Things, wearable computing, objective metrics, and the quantified self 2.0. J. Sens. Actuator Netw. 1, 217-253 (2012).

2. Park, J. et al. Wearable, wireless gas sensors using highly stretchable and transparent structures of nanowires and graphene. Nanoscale 8, 10591-10597 (2016).

3. Kampa, M. \& Castanas, E. Human health effects of air pollution. Environ. Pollut. 151, 362-367 (2008).

4. Naguib, M. et al. Two-dimensional transition metal carbides. ACS Nano 6, 1322-1331 (2012).

5. Peng, J., Chen, X., Ong, W. J., Zhao, X. \& Li, N. Surface and heterointerface engineering of 2D MXenes and their nanocomposites: insights into electroand photocatalysis. Chem 5, 18-50 (2019).

6. Ding, X. et al. Defect engineered bioactive transition metals dichalcogenides quantum dots. Nat. Commun. 10, 41 (2019).
7. Gogotsi, Y. \& Anasori, B. The rise of MXenes. ACS Nano 13, 8491-8494 (2019).

8. Pang, J. et al. Applications of 2D MXenes in energy conversion and storage systems. Chem. Soc. Rev. 48, 72-133 (2019).

9. Chaudhari, N. K. et al. MXene: an emerging two-dimensional material for future energy conversion and storage applications. J. Mater. Chem. A 5, 24564-24579 (2017)

10. Anasori, B., Lukatskaya, M. R. \& Gogotsi, Y. 2D metal carbides and nitrides (MXenes) for energy storage. Nat. Rev. Mater. 2, 16098 (2017).

11. Lin, H., Chen, Y. \& Shi, J. Insights into 2D MXenes for versatile biomedical applications: current advances and challenges ahead. Adv. Sci. 5, 1800518 (2018).

12. Sinha, A. et al. MXene: an emerging material for sensing and biosensing. TracTrends Anal. Chem. 105, 424-435 (2018).

13. Sun, W. \& Wu, F. G. Two-dimensional materials for antimicrobial applications: graphene materials and beyond. Chem. Asian J. 13, 3378-3410 (2018).

14. Junkaew, A. \& Arroyave, R. Enhancement of the selectivity of MXenes $\left(\mathrm{M}_{2} \mathrm{C}\right.$, $\mathrm{M}=\mathrm{Ti}, \mathrm{V}, \mathrm{Nb}, \mathrm{Mo}$ ) via oxygen-functionalization: promising materials for gas-sensing and -separation. Phys. Chem. Chem. Phys. 20, 6073-6082 (2018).

15. Lee, E., VahidMohammadi, A., Yoon, Y. S., Beidaghi, M. \& Kim, D. J. Twodimensional vanadium carbide MXene for gas sensors with ultrahigh sensitivity toward nonpolar gases. ACS Sens. 4, 1603-1611 (2019).

16. Koh, H. J. et al. Enhanced selectivity of MXene gas sensors through metal ion intercalation: in situ X-ray diffraction study. ACS Sens. 4, 1365-1372 (2019).

17. Dwivedi, P., Das, S. \& Dhanekar, S. Wafer-scale synthesized $\mathrm{MoS}_{2} /$ porous silicon nanostructures for efficient and selective ethanol sensing at room temperature. ACS Appl. Mater. Interfaces 9, 21017-21024 (2017).

18. Ko, K. Y. et al. Improvement of gas-sensing performance of large-area tungsten disulfide nanosheets by surface functionalization. ACS Nano 10, 9287-9296 (2016)

19. Ping, J., Fan, Z., Sindoro, M., Ying, Y. \& Zhang, H. Recent advances in sensing applications of two-dimensional transition metal dichalcogenide nanosheets and their composites. Adv. Funct. Mater. 27, 1605817 (2017).

20. Feng, S., Lin, Z., Gan, X., Lv, R. \& Terrones, M. Doping two-dimensional materials: ultra-sensitive sensors, band gap tuning and ferromagnetic monolayers. Nanoscale Horiz. 2, 72-80 (2017).

21. Joshi, N. et al. A review on chemiresistive room temperature gas sensors based on metal oxide nanostructures, graphene and 2D transition metal dichalcogenides. Microchim. Acta 185, 213 (2018).

22. Lee, E., Yoon, Y. S. \& Kim, D. J. Two-dimensional transition metal dichalcogenides and metal oxide hybrids for gas sensing. ACS Sens. 3, 2045-2060 (2018)

23. Sajedi-Moghaddam, A., Saievar-Iranizad, E. \& Pumera, M. Two-dimensional transition metal dichalcogenide/conducting polymer composites: synthesis and applications. Nanoscale 9, 8052-8065 (2017).

24. Thanh, T. D. et al. Recent advances in two-dimensional transition metal dichalcogenides-graphene heterostructured materials for electrochemical applications. Prog. Mater. Sci. 96, 51-85 (2018).

25. Liu, X., Ma, T., Pinna, N. \& Zhang, J. Two-dimensional nanostructured materials for gas sensing. Adv. Funct. Mater. 27, 1702168 (2017).

26. Xiong, D., Li, X., Bai, Z. \& Lu, S. Recent advances in layered $\mathrm{Ti}_{3} \mathrm{C}_{2} \mathrm{~T}_{\mathrm{x}}$ MXene for electrochemical energy storage. Small 14, 1703419 (2018).

27. Tan, C. \& Zhang, H. Two-dimensional transition metal dichalcogenide nanosheet-based composites. Chem. Soc. Rev. 44, 2713-2731 (2015).

28. Gupta, A., Sakthivel, T. \& Seal, S. Recent development in 2D materials beyond graphene. Prog. Mater. Sci. 73, 44-126 (2015).

29. Grayfer, E. D., Kozlova, M. N. \& Fedorov, V. E. Colloidal 2D nanosheets of $\mathrm{MoS}_{2}$ and other transition metal dichalcogenides through liquid-phase exfoliation. Adv. Colloid Interface Sci. 245, 40-61 (2017).

30. Ying, Y. et al. Two-dimensional titanium carbide for efficiently reductive removal of highly toxic chromium(VI) from water. ACS Appl. Mater. Interfaces 7, 1795-1803 (2015).

31. Alhabeb, M. et al. Guidelines for synthesis and processing of two-dimensional titanium carbide $\left(\mathrm{Ti}_{3} \mathrm{C}_{2} \mathrm{~T}_{\mathrm{x}}\right.$ MXene). Chem. Mater. 29, 7633-7644 (2017).

32. Ding, L. et al. MXene molecular sieving membranes for highly efficient gas separation. Nat. Commun. 9, 155 (2018).

33. Lipatov, A. et al. Effect of synthesis on quality, electronic properties and environmental stability of individual monolayer $\mathrm{Ti}_{3} \mathrm{C}_{2}$ MXene flakes. $A d v$. Electron. Mater. 2, 1600255 (2016).

34. Ko, K. Y. et al. High-performance gas sensor using a large-area $\mathrm{WS}_{2 \mathrm{x}} \mathrm{Se}_{2-2 \mathrm{x}}$ alloy for low-power operation wearable applications. ACS Appl. Mater. Interfaces 10, 34163-34171 (2018).

35. Rakhi, R. B., Ahmed, B., Hedhili, M. N., Anjum, D. H. \& Alshareef, H. N. Effect of postetch annealing gas composition on the structural and electrochemical properties of $\mathrm{Ti}_{2} \mathrm{CT}_{\mathrm{x}}$ MXene electrodes for supercapacitor applications. Chem. Mater. 27, 5314-5323 (2015).

36. Shah, $\mathrm{S}$. A. et al. Template-free $3 \mathrm{D}$ titanium carbide $\left(\mathrm{Ti}_{3} \mathrm{C}_{2} \mathrm{~T}_{\mathrm{x}}\right)$ MXene particles crumpled by capillary forces. Chem. Commun. 53, 400-403 (2016). 
37. Liu, Y. T. et al. Self-assembly of transition metal oxide nanostructures on MXene nanosheets for fast and stable lithium storage. Adv. Mater. 30, 1707334 (2018).

38. Du, C. F. et al. Self-assemble and in situ formation of $\mathrm{Ni}_{1-\mathrm{x}} \mathrm{Fe}_{\mathrm{x}} \mathrm{PS}_{3}$ nanomosaic-decorated MXene hybrids for overall water splitting. Adv. Energy Mater. 8, 1801127 (2018).

39. Ran, J. et al. $\mathrm{Ti}_{3} \mathrm{C}_{2}$ MXene co-catalyst on metal sulfide photo-absorbers for enhanced visible-light photocatalytic hydrogen production. Nat. Commun. 8, 13907 (2017).

40. He, Q. et al. Fabrication of flexible $\mathrm{MoS}_{2}$ thin-film transistor arrays for practical gas-sensing applications. Small 8, 2994-2999 (2012).

41. Kim, S. J. et al. Metallic $\mathrm{Ti}_{3} \mathrm{C}_{2} \mathrm{~T}_{\mathrm{x}}$ MXene gas sensors with ultrahigh signal-tonoise ratio. ACS Nano 12, 986-993 (2018).

42. Dillon, A. D. et al. Highly conductive optical quality solution-processed films of 2D titanium carbide. Adv. Funct. Mater. 26, 4162-4168 (2016).

43. Cho, S. Y. et al. High-resolution p-type metal oxide semiconductor nanowire array as an ultrasensitive sensor for volatile organic compounds. Nano Lett. 16, 4508-4515 (2016).

44. Li, B. et al. Asymmetric MXene/monolayer transition metal dichalcogenide heterostructures for functional applications. Npj Comput. Mater. 5, 1-8 (2019).

45. Zhao, X. et al. Antioxidants unlock shelf-stable $\mathrm{Ti}_{3} \mathrm{C}_{2} \mathrm{~T}$ (MXene) nanosheet dispersions. Matter 1, 513-526 (2019).

46. Cui, S., Wen, Z., Huang, X., Chang, J. \& Chen, J. Stabilizing $\mathrm{MoS}_{2}$ nanosheets through $\mathrm{SnO}_{2}$ nanocrystal decoration for high-performance gas sensing in air. Small 11, 2305-2313 (2015).

47. $\mathrm{Ma}, \mathrm{H}$. et al. Highly toluene sensing performance based on monodispersed $\mathrm{Cr}_{2} \mathrm{O}_{3}$ porous microspheres. Sens. Actuator B-Chem. 174, 325-331 (2012).

48. Zhang, C. J. et al. Oxidation stability of colloidal two-dimensional titanium carbides (MXenes). Chem. Mater. 29, 4848-4856 (2017).

49. Habib, $\mathrm{T}$. et al. Oxidation stability of $\mathrm{Ti}_{3} \mathrm{C}_{2} \mathrm{~T}_{\mathrm{x}}$ MXene nanosheets in solvents and composite films. NPJ 2D Mater. Appl. 3, 8 (2019).

50. Hoppe, $\mathrm{M}$. et al. ( $\mathrm{CuO}-\mathrm{Cu} 2 \mathrm{O}) / \mathrm{ZnO}: \mathrm{Al}$ heterojunctions for volatile organic compound detection. Sens. Actuator B-Chem. 255, 1362-1375 (2018).

51. Backes, C. et al. Production of highly monolayer enriched dispersions of liquid-exfoliated nanosheets by liquid cascade centrifugation. ACS Nano 10, 1589-1601 (2016).

52. Yao, Y. et al. High-concentration aqueous dispersions of $\mathrm{MoS}_{2}$. Adv. Funct. Mater. 23, 3577-3583 (2013).

53. Chen, W. Y., Yen, C. C., Xue, S., Wang, H. \& Stanciu, L. A. Surface functionalization of layered molybdenum disulfide for the selective detection of volatile organic compounds at room temperature. ACS Appl. Mater. Interfaces 11, 34135-34143 (2019).

\section{Acknowledgements}

The authors wish to thank the Birck Nanotechnology Center, Purdue University, for providing equipment and technical support.

\section{Author contributions}

W.Y.C. and L.S. directed the research and experiments; X.J. and D.P. provided the wireless sensing electronics; S.N.L. did the XPS and data analysis; W.Y.C. and L.S. cowrote the manuscript with input from all authors.

\section{Competing interests}

The authors declare no competing interests.

\section{Additional information}

Supplementary information is available for this paper at https://doi.org/10.1038/s41467020-15092-4.

Correspondence and requests for materials should be addressed to L.S.

Peer review information Nature Communication thanks anonymous reviewers for their contributions to the peer review of this work.

Reprints and permission information is available at http://www.nature.com/reprints

Publisher's note Springer Nature remains neutral with regard to jurisdictional claims in published maps and institutional affiliations.

Open Access This article is licensed under a Creative Commons Attribution 4.0 International License, which permits use, sharing, adaptation, distribution and reproduction in any medium or format, as long as you give appropriate credit to the original author(s) and the source, provide a link to the Creative Commons license, and indicate if changes were made. The images or other third party material in this article are included in the article's Creative Commons license, unless indicated otherwise in a credit line to the material. If material is not included in the article's Creative Commons license and your intended use is not permitted by statutory regulation or exceeds the permitted use, you will need to obtain permission directly from the copyright holder. To view a copy of this license, visit http://creativecommons.org/ licenses/by/4.0/

(C) The Author(s) 2020 